\title{
Modification of cement-based materials with nanoparticles
}

\author{
Shiho Kawashima ${ }^{\mathrm{a}, *}$, Pengkun Hou ${ }^{\mathrm{a}, \mathrm{b}}$, David J. Corr ${ }^{\mathrm{a}}$, Surendra P. Shah ${ }^{\mathrm{a}}$ \\ ${ }^{a}$ Department of Civil and Environmental Engineering, Northwestern University, 2145 Sheridan Road, A236, Evanston, IL 60208, United States \\ ${ }^{\mathrm{b}}$ College of Materials Science and Engineering, Chongqing University, Chongqing 400045, PR China
}

\section{A R T I C L E I N F O}

\section{Article history:}

Received 1 February 2012

Received in revised form 30 April 2012

Accepted 7 June 2012

Available online 27 June 2012

\section{Keywords:}

Clay

$\mathrm{NanoCaCO}_{3}$

$\mathrm{NanoSiO}_{2}$

Fly ash

Rheology

Nanomodification

\begin{abstract}
A B S T R A C T
This is a summary paper on the work being done at the Center for Advanced Cement-Based Materials at Northwestern University on the modification of cement-based materials with nanoparticles, specifically nanoclays, calcium carbonate nanoparticles, and nanosilica. The rheological properties of clay-modified cement-based materials are investigated to understand the influence of nanoclays on thixotropy. The influence of the method of dispersion of calcium carbonate nanoparticles on rate of hydration, setting, and compressive strength are evaluated. And an in-depth study on the mechanisms underlying the influence of nanosilica on the compressive strength gain of fly ash-cement systems is discussed. The motivation behind these studies is that with proper processing techniques and fundamental understanding of the mechanisms underlying the effect of the nanoparticles, they can be used to enhance the fresh-state and hardened properties of cement-based materials for various applications. Nanoclays can increase the green strength of self-consolidating concrete for reduced formwork pressure and slipform paving. Calcium carbonate nanoparticles and nanosilica can offset the negative effects of fly ash on early-age properties to facilitate the development of a more environmentally friendly, high-volume fly ash concrete.
\end{abstract}

(c) 2012 Elsevier Ltd. All rights reserved.

\section{Introduction}

Due to the complexity of concrete, which is heterogeneous at all length scales, and the recent innovations in nanotechnology, nanomodification of cement-based materials has generated much research interest. Nanomodification is the manipulation of the structure at the nanoscale (less than $100 \mathrm{~nm}$ ) to develop cement composites that exhibit enhanced or novel properties and functions. Carbon nanotubes (CNTs) dispersed by ultrasonication can significantly improve the flexural strength of cement composites by controlling cracks at the nanoscale [1]. Through other mechanisms, often attributed to filler and/or seeding effects, nanoparticles can accelerate rate of hydration and improve early-age mechanical properties of cementitious materials, including those with cement replacement by fly ash. Among the types of nanoparticles investigated are titanium dioxide $\left(\mathrm{TiO}_{2}\right)$ nanoparticles [2], zinc dioxide $\left(\mathrm{ZnO}_{2}\right)$ nanoparticles [3], calcium carbonate $\left(\mathrm{CaCO}_{3}\right)$ nanoparticles [4,5], and nanoclays [6], although the majority of studies thus far have focused on nanosilica [7-12]. However, due to the novelty of the technology, more investigation needs to be done to further understand the mechanisms underlying the effect

\footnotetext{
* Corresponding author. Tel.: +1 847491 7161(O).

E-mail address: s-kawashima@northwestern.edu (S. Kawashima).
}

of the nanoparticles, to improve processing, and to evaluate their influence at later-ages.

At the Center for Advanced Cement-Based Materials at Northwestern University (ACBM-NU), work is being done on modifying the fresh-state and hardened properties of cement-based systems (including those containing fly ash) with nanoclays, nanoC$\mathrm{aCO}_{3}$ and nanoSiO${ }_{2}$. This paper is a summary of the current studies. The rheological properties of nanoclay-modified cement-based materials are investigated to further understand the influence of nanoclays on fresh-state stiffening and formwork pressure. The influence of the method of dispersion of nanoCaCO $\mathrm{C}_{3}$ powder on early-age properties is evaluated. And an in-depth study on the mechanisms underlying the influence of nanoSiO ${ }_{2}$ on the compressive strength gain of fly ash-cement systems is discussed.

With proper processing techniques and fundamental understanding of the mechanisms underlying the effect of the nanoparticles, they can be used to enhance the fresh-state and hardened properties of cement-based materials for various applications. Nanoclays can increase the green strength of self-consolidating concrete (SCC) for reduced formwork pressure and slipform paving. NanoCaCO 3 and nanoSiO 2 can offset the negative effects of fly ash on early-age properties, namely slowed rate of hydration and compressive strength gain, to facilitate the development of a more environmentally friendly, highvolume fly ash concrete. 


\section{Experimental methods and materials}

\subsection{Material properties}

Tap water and ordinary Portland cement (OPC) were used in all mixes, along with a type F fly ash in select mixes. The chemical properties are given in Table 1 . The fly ash particles are round with a size range of 2-20 microns, as shown in the scanning electron microscopy (SEM) image, Fig. 1a. The spherical morphology of fly ash helps increase the flowability of cementitious materials, including those with nanoparticles, which increase stiffness due to their high specific surface area.

The three types of nanoparticles used in the current studies are nanoclay, nanoCaCO $\mathrm{C}_{3}$, and nanoSiO${ }_{2}$. The nanoclay was a purified magnesium aluminosilicate, or palygorskite, with a rod-like shape ( $1.75 \mu \mathrm{m}$ in length, $3 \mathrm{~nm}$ in diameter). The nanoclay has been chemically exfoliated to preserve its uniform shape and size while removing all impurities (such as quartz and swelling clays). As received, they are highly-agglomerated. To disperse the nanoclay, they are blended with water in a household blender prior to mixing with the other dry ingredients. The nanoCaCO${ }_{3}$ came in dry powder form, with a particle size range of $15-40 \mathrm{~nm}$. Similarly to the nanoclay, they are agglomerated to the micron scale in the as-received state. Two types of colloidal nanoSiO ${ }_{2}$ (CNS) with an average particle size of $20 \mathrm{~nm}$ (CNS-20) and $10 \mathrm{~nm}$ (CNS-10) were used. The transmission electron microscopy (TEM) images of CNS-10 (Fig. 1b) and CNS-20 (Fig. 1c) indicate that most of the nanoparticles are well-dispersed, although some agglomeration may occur.

\subsection{Testing procedures}

Shear rheological tests were performed in a temperature-controlled rheometer with a coaxial cylinder geometry set at room temperature. The rate of hydration of pastes were measured in a semi-adiabatic calorimeter, where a sample was placed in an insulated drum and its temperature change was recorded for $24 \mathrm{~h}$. ASTM C191 was followed to measure initial and final setting time of pastes with a manual Vicat needle apparatus [13]. ASTM C230 was followed to measure the slump flow of mortars using a flow table [14].

ASTM C109 was followed to measure the compressive strength of pastes or mortars with a $1000 \mathrm{kip}(4448 \mathrm{kN})$ MTS hydraulic testing machine [15] - the loading rate of the test was $0.008 \mathrm{~mm} / \mathrm{s}$. For each mix at each age, three samples were tested and the average value was taken to be the representative strength.

Thermogravimetric analysis (TGA, TGA/sDTA 851) was carried out to measure the calcium hydroxide $(\mathrm{CH})$ content of samples. Samples of about $20 \mathrm{mg}$ were heated at atmospheric pressure at a rate of $15^{\circ} \mathrm{C} / \mathrm{min}$. The weight loss between $440{ }^{\circ} \mathrm{C}$ and $510{ }^{\circ} \mathrm{C}$ was considered to be the decomposition of $\mathrm{CH}$. Before measuring, samples were oven - dried at $105^{\circ} \mathrm{C}$ for $4 \mathrm{~h}$.

Table 1

Chemical properties of cement and fly ash.

\begin{tabular}{lll}
\hline Materials & Type I cement & Type F fly ash \\
\hline $\mathrm{SiO}_{2}$ & 20.2 & 46 \\
$\mathrm{Al}_{2} \mathrm{O}_{3}$ & 4.7 & 17.8 \\
$\mathrm{Fe}_{2} \mathrm{O}_{3}$ & 3.3 & 18.2 \\
$\mathrm{SO}_{3}$ & 3.3 & 2.59 \\
$\mathrm{CaO}$ & 62.9 & 8.4 \\
$\mathrm{MgO}$ & 2.7 & 0.95 \\
$\mathrm{Na}$ & - & 0.59 \\
$\mathrm{~K}_{2} \mathrm{O}$ & - & 2.16 \\
$\mathrm{LOI}$ & 1.1 & 1.49 \\
$\mathrm{Total}$ & 98.2 & 98.2 \\
\hline
\end{tabular}

Hitachi S-4800 FE-SEM equipped with energy dispersive spectroscope (EDS) was used to analyze the morphology and elemental compositions of the cement paste. A small fractured sample was

(a)

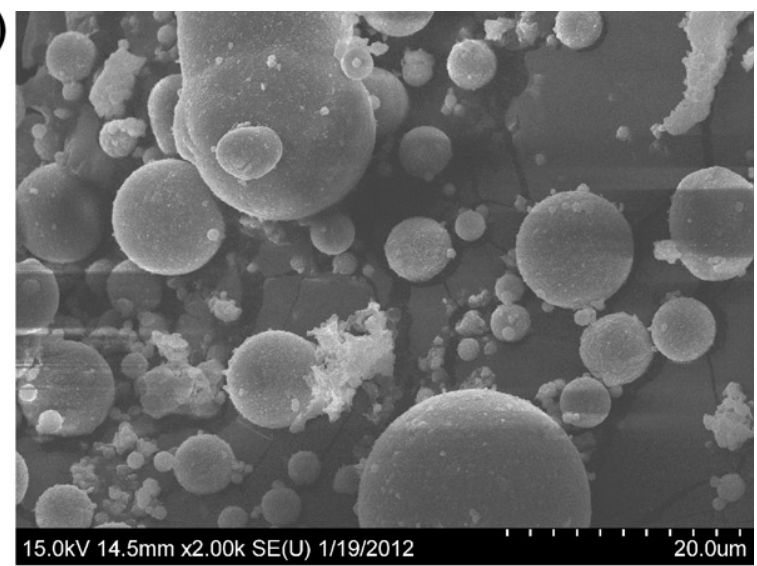

(b)

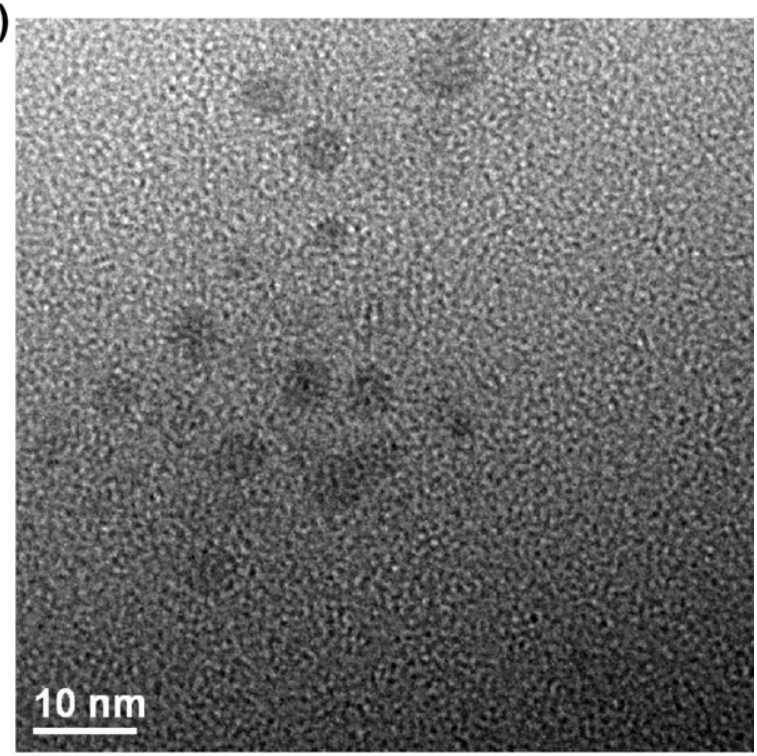

(c)

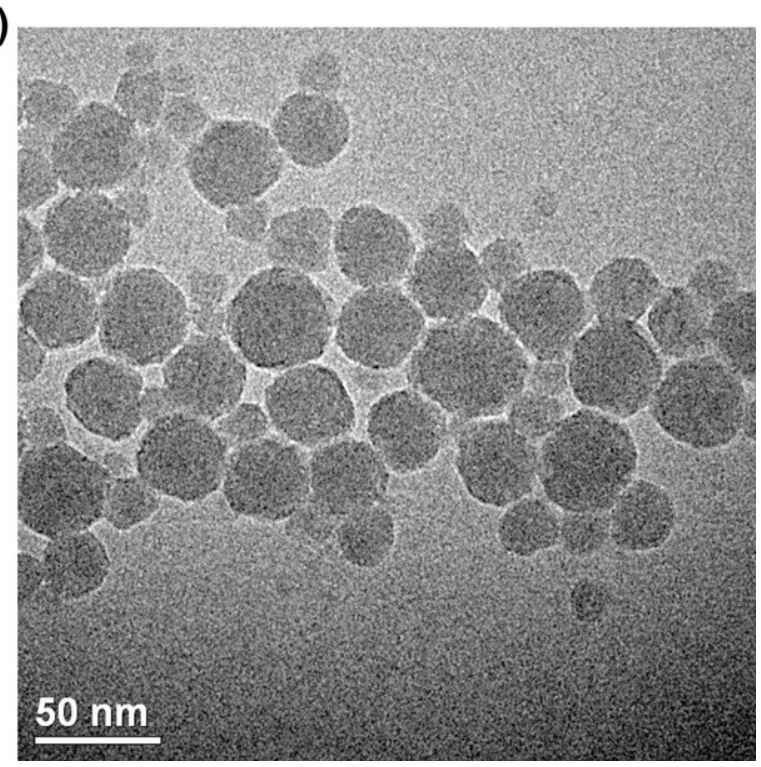

Fig. 1. Morphology of (a) fly ash (SEM), (b) CNS-10 nm (TEM) and (c) CNS-20 nm (TEM). 
soaked in acetone to stop hydration and dried at $80^{\circ} \mathrm{C}$ for $2 \mathrm{~h}$. Then the sample was coated with $20 \mathrm{~nm}$ of gold to make it conductive. The accelerating voltage and current were $15-20 \mathrm{kV}$ and $10-20 \mu \mathrm{A}$, respectively. The upper detector was used to collect the secondary electrons. Hitachi $\mathrm{H}-8100$ was used to analyze the morphology of the nanoSiO 2 . Samples were diluted in alcohol before testing and the accelerating voltage and current were $200 \mathrm{kV}$ and $10 \mu \mathrm{A}$, respectively.

\section{Nanoclays}

Previous work at ACBM has demonstrated that proper proportioning of fly ash, superplasticizer, and a small addition of clays ( $<1 \%$ by mass of binder) can significantly increase the green strength of SCC mixes immediately after casting with little compromise to initial flowability [16-19]. Such properties can effectively reduce SCC formwork pressure. Fig. 2 shows the formwork pressure response of SCC mixes with and without a $0.33 \%$ nanoclay addition by mass of binder - NC0.33 and NC0, respectively. These are the results from a previous study [20], where a lab-scale formwork pressure device was used to simulate casting by applying a vertical pressure and measure the lateral pressure over time. It is apparent that the clays significantly reduced lateral pressure. This behavior has previously been tied to flocculation behavior, where studies have shown that clays increase flocculation strength [21] and floc size [22]. In the study discussed here, the contribution of water adsorption by the clays on stiffening was examined through a shear rheological approach [23]. If the water content is kept constant, the incorporation of any nanoparticle will lead to an increase in stiffness due to increase in water demand. The nanoclays have a high water adsorption of $200 \%$ by mass, making it a possible governing factor.

\subsection{Constant applied shear rate (CR) protocol}

The water content of cement pastes with and without a $1 \%$ nanoclay addition by mass of cement were adjusted for clay water adsorption (assuming 200\% water adsorption by mass). The paste mix compositions are given in Table 2. Each mix was subjected to a constant applied shear rate of $300 \mathrm{~s}^{-1}$ for $60 \mathrm{~min}$, during which the tangent viscosity was calculated from the measured shear stress as follows:

$\mu=\frac{\tau}{\dot{\gamma}}$

where $\mu$ is viscosity (Pa s), $T$ is shear stress (Pa) and $\dot{\gamma}$ is applied shear rate $\left(\mathrm{s}^{-1}\right)$.

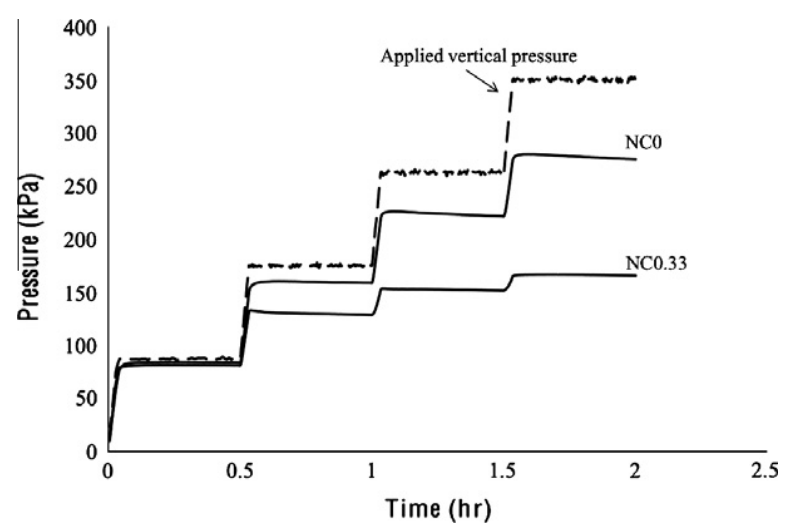

Fig. 2. Formwork pressure response of SCC with and without a $0.33 \%$ nanoclay addition [20].
Table 2

Mix composition of pastes for $\mathrm{CR}$ protocol, where $\mathrm{NCO}$ is the control for $\mathrm{NC1H}$ and $\mathrm{NC} 1$ is the control for $\mathrm{NCOH}$.

\begin{tabular}{llll}
\hline Mix & Cement $(\mathrm{g})$ & Water $(\mathrm{g})$ & Clay $(\mathrm{g})$ \\
\hline NC0 & 500 & 215 & 0 \\
NC1 & 500 & 217.6 & 5 \\
NC1H & 500 & 227.6 & 5 \\
NCOH & 500 & 205 & 0 \\
\hline
\end{tabular}
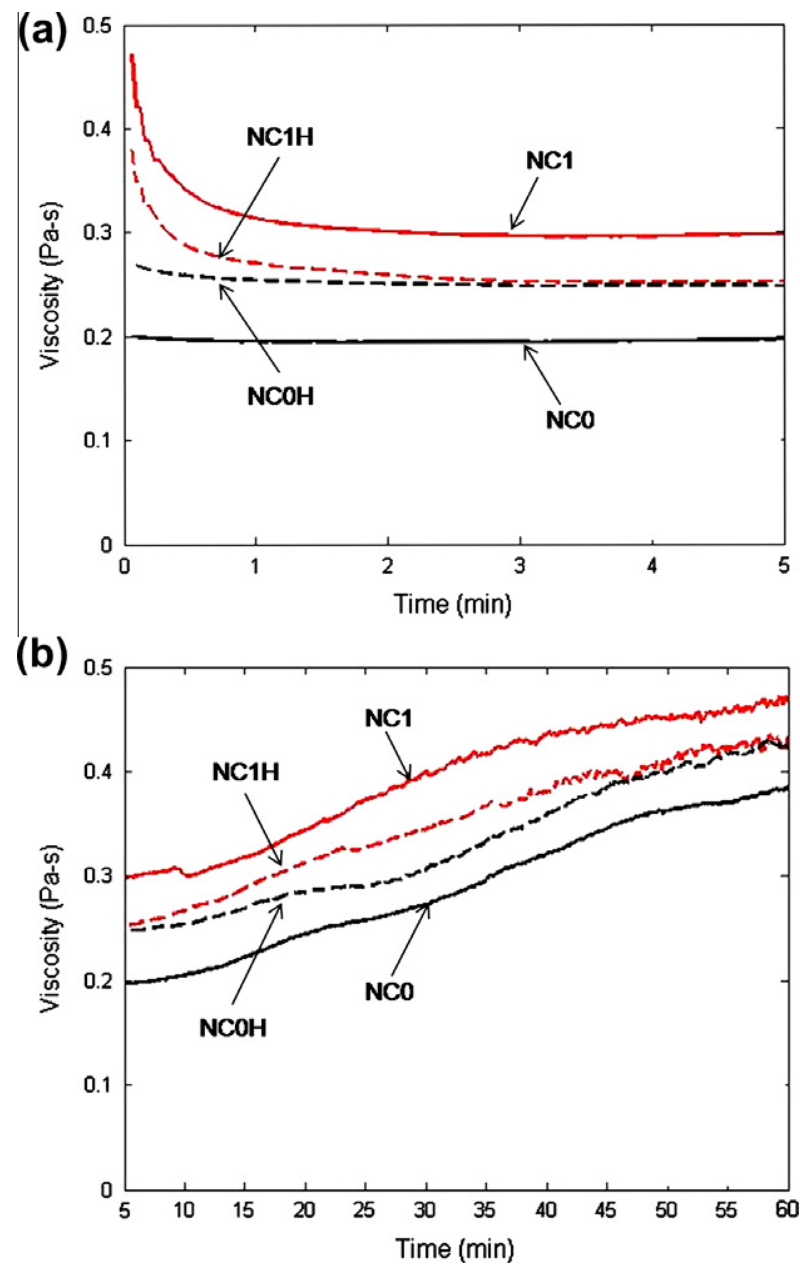

Fig. 3. Viscosity evolution of pastes (a) before and (b) after equilibrium [23].

The results are shown in Fig. 3. Fig. 3a shows the viscosity evolution up to $5 \mathrm{~min}$, during which each mix reached equilibrium (steady-state). At this point the flocs cannot be broken down any further under the given shear condition. If the loss of free water by clay water adsorption is a governing stiffening mechanism, mixes $\mathrm{NCO}$ and $\mathrm{NC} 1 \mathrm{H}$ and mixes $\mathrm{NC} 1$ and $\mathrm{NCOH}$ should exhibit similar viscosity evolutions. However, it is apparent that the viscosities of these mixes did not coincide and adjusting water content did not offset the stiffening effect of the clays. Also, both mixes with clays exhibited a significant decrease in viscosity upon the introduction of shear due to deflocculation. This shows that the clays had an immediate stiffening effect through flocculation, resulting in a highly thixotropic material.

After equilibrium, each paste goes onto experience a similar increase in viscosity, as shown in Fig. 3b. Table 3 shows that the change in viscosity of all the mixes from equilibrium to final (60 min) were very close. This indicates that although the clays 
Table 3

Change in viscosity from equilibrium to final (60 min).

\begin{tabular}{ll}
\hline Mix & $\Delta$ Viscosity (Pa s) \\
\hline NCO & 0.192 \\
NC1 & 0.175 \\
NC1H & 0.18 \\
NCOH & 0.176 \\
\hline
\end{tabular}

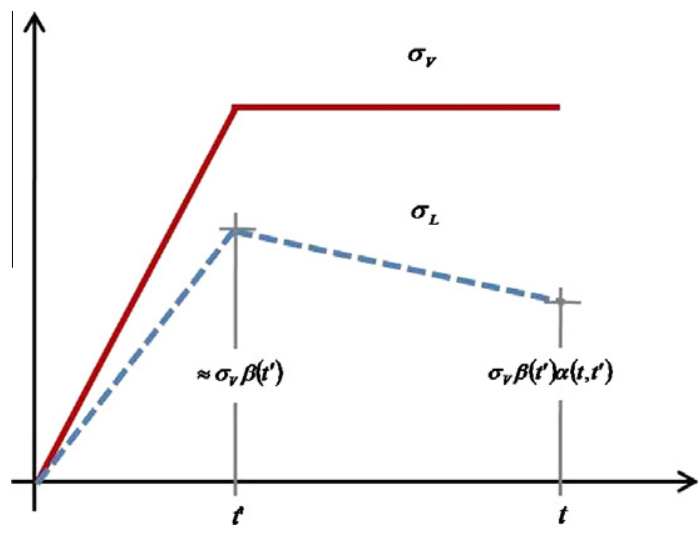

Fig. 4. Two function model for formwork pressure of concrete [24].

have an immediate stiffening effect, they have little or no influence over time under a given constant shear condition. This will be tied into previously obtained formwork pressure results and discussed in the following section.

\subsection{Formwork pressure}

In the formwork pressure test introduced earlier, the vertical pressure was applied as a step-wise function, Fig. 2. As shown in Fig. 4, this allows for an instantaneous response, $\beta$, and a delayed response, $\alpha$, to be measured. This two function model was introduced by Kwon et al. and Kim et al., the details of which can be found elsewhere [24,25]. While the concrete is plastic, $\alpha$ and $\beta$ can be represented in terms of delayed coefficient, $a$, and instantaneous coefficient, $b$, both of which are material parameters:

$\alpha\left(t, t^{\prime}\right)=1-a^{2} t^{\prime}\left(t-t^{\prime}\right)$

$\beta\left(t^{\prime}\right)=1-b t^{\prime}$

$t$ is current time and $t^{\prime}$ is time of loading. The delayed and instantaneous responses of $\mathrm{NCO}$ and $\mathrm{NC} 0.33$ over a $2 \mathrm{~h}$ casting period are plotted in Fig. 5. The clays have little influence over the delayed response - the rate at which the lateral pressure decreases as the applied vertical pressure is held constant is the same for both mixes, Fig. 5a. However, the clays significantly reduce the instantaneous response - the lateral pressure is significantly lower upon each incremental increase in pressure, Fig. 5b. These results are similar to those of the CR test, where the clays exhibit an immediate effect upon a change in applied stress but little influence over time under a constant condition.

Kim et al. used the two-function model to characterize a variety of different SCC mixes [24]. They found that variation in coefficient a had a negligible effect on the maximum formwork pressure, $\sigma_{\max }$ while variation in $\mathrm{b}$ had a dominant one during the first few hours of casting. For the design of formwork, $\sigma_{\max }$ is a critical value. It follows that since the nanoclays significantly affect $b$, they have the capacity to greatly reduce $\sigma_{\max }$.
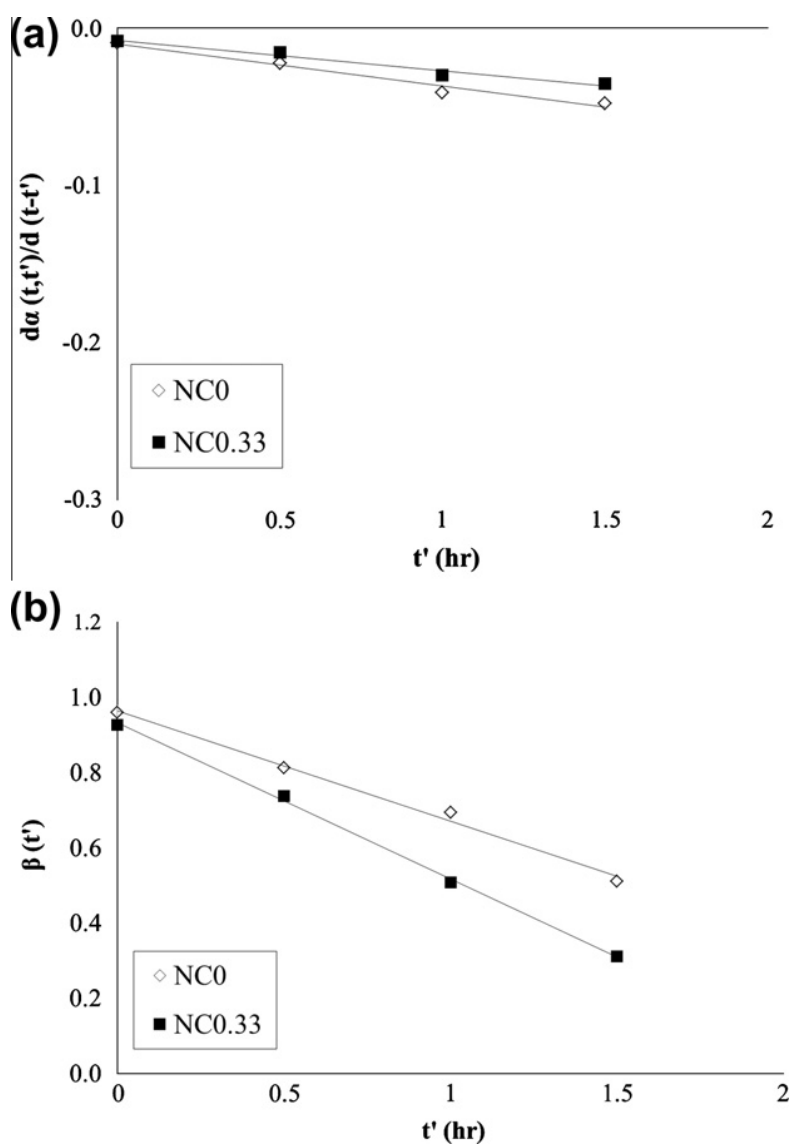

Fig. 5. (a) Delayed and (b) instantaneous formwork pressure response of SCC with and without a $0.33 \%$ nanoclay addition.

\section{Calcium carbonate nanoparticles}

Although limestone powder is typically considered to be inert, conventionally used as a filler to improve rheological properties, recent studies have found that they can accelerate rate of hydration when introduced as nanoparticles [4,5]. However, few in-depth studies have been done thus far. This study focuses on processing, where dry nanoCaCO $\mathrm{C}_{3}$ powder is dispersed through ultrasonication. This method has been successfully implemented to disperse carbon nanotubes and significantly improve the mechanical properties of cement composites [1]. Through effective dispersion, the motivation is to enhance the effect of the nanoparticles and to decrease the addition level necessary.

In the present study, the effect of sonicated versus blended nanoCaCO 3 on rate of hydration, setting time, and early-age compressive strength gain were compared in cement and fly ash-cement pastes. NanoCaCO 3 was sonicated for $30 \mathrm{~min}$ in an aqueous solution at $15 \%$ concentration. And $0.06 \%$ polycarboxylate superplasticizer (by weight of water) was added to the suspension to help with stabilization. Suspensions prepared by blending were prepared in a household blender for 3 min.

\subsection{Rate of hydration}

The rate of hydration of OPC pastes was measured through semi-adiabatic calorimetry. All samples had a water-to-cement $(w / c)$ ratio of 0.43 , with or without a $5 \%$ nanoCaCO $\mathrm{Caddition} \mathrm{by}_{3}$ mass of cement. Pastes with nanoCaCO $\mathrm{C}_{3}$ were prepared with a suspension that was sonicated or blended. The results are shown in Fig. 6. It is apparent that for both samples with a nanoCaCO addition, there is an acceleration in rate of hydration. However, 


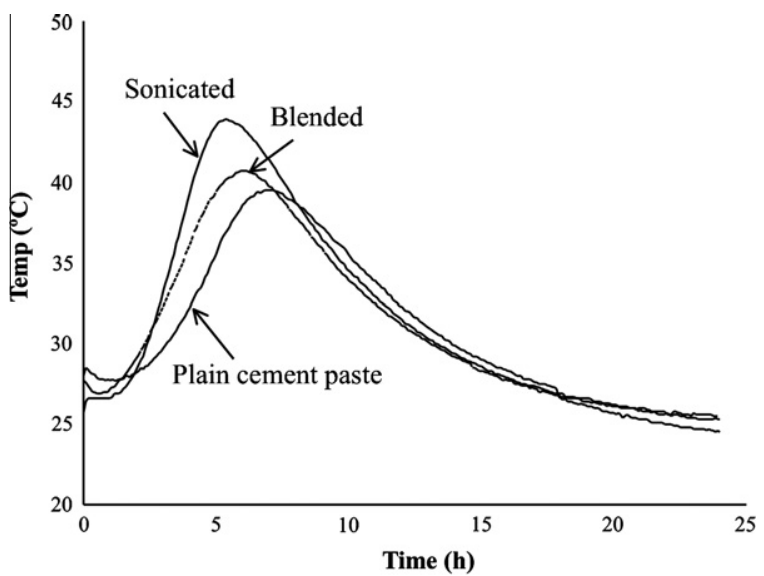

Fig. 6. Semi-adiabatic calorimetry results for cement pastes with a $5 \%$ nanoCaCO addition, prepared by sonication or blending, and plain cement paste.

Table 4

Setting time of $50 \%$ fly ash OPC pastes with and without a $5 \%$ nanoCaCO 3 addition, prepared by blending or sonication, compared to plain OPC paste.

\begin{tabular}{lll}
\hline & Initial setting/h & Final setting/h \\
\hline 50FA & 6.2 & 7.4 \\
$50 \mathrm{FA} 5 \mathrm{CaCO}_{3}$ (Blended) & 4.8 & 6.1 \\
$50 \mathrm{FA} \mathrm{5CaCO}$ (Sonicated) & 4.4 & 5.4 \\
Plain OPC & 4.4 & 5.4 \\
\hline
\end{tabular}

the effect is more pronounced for the sonicated sample, where the peak is higher and occurs earlier.

\subsection{Setting}

The setting time of pastes with a 50\% replacement of cement with fly ash were measured and compared against a plain OPC paste. All samples had a water-to-binder $(w / b)$ ratio of 0.4 , with or without a $5 \%$ nanoCaCO 3 addition. The results are shown in Table 4 . In both cases, blended and sonicated, the addition of $5 \%$ nanoCaCO 3 helped accelerate setting. Further, the sonicated nanoCaCO $\mathrm{Completely}_{3}$ offset the delay caused by the $50 \%$ fly ash replacement, where it exhibited the same setting times as the plain OPC paste sample.

\subsection{Compressive strength}

The compressive strength gain $(1,3$, and $7 \mathrm{~d})$ of $50 \mathrm{~mm}$ cube samples were compared for an OPC paste and 30\% fly ash-cement

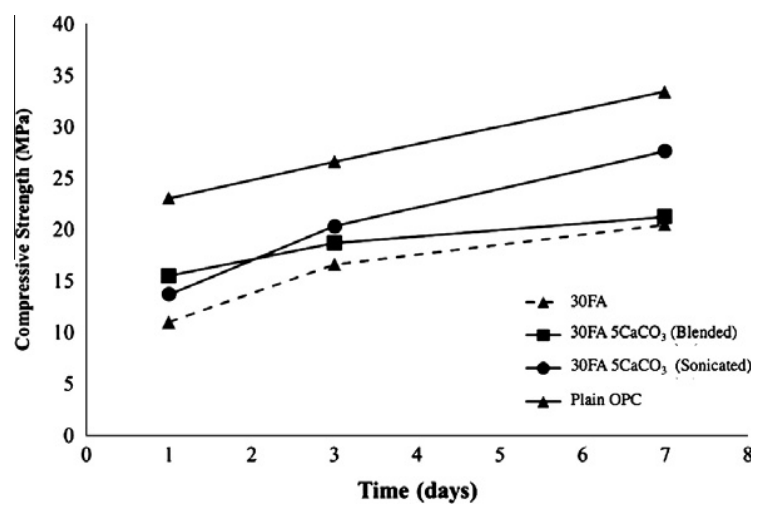

Fig. 7. Compressive strength gain of $30 \%$ fly ash OPC pastes with and without a $5 \%$ nanoCaCO $\mathrm{C}_{3}$ addition, prepared by blending or sonication, compared to plain OPC paste. pastes with and without a $5 \%$ nanoCaCO $\mathrm{CO}_{3}$ addition. All pastes had a $w / b=0.43$. The results are shown in Fig. 7 . At 3 and $7 \mathrm{~d}$, the sonicated sample showed a greater improvement than the blended sample. However, neither reached the strength of the OPC sample. Work on modifying the sonication protocol to improve the stability

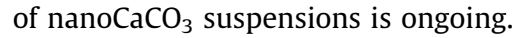

\section{5. $\mathrm{NanoSiO}_{2}$}

Although high volume fly ash introduces the advantage of increasing the workability of cementitious materials, its slow early-age strength gain is a major drawback and has hindered its application. With the incorporation of nanoSiO ${ }_{2}$, the strength gain of cement-based materials can be improved due to its hydration seeding effect and high pozzolanic activity [8,10,26,27], which result in a higher amount of $\mathrm{C}-\mathrm{S}-\mathrm{H}$ gel and more densified bulk structure [28]. However, the shortcoming of nanoSiO${ }_{2}$-modified cement-based material is that the nanoSiO${ }_{2}$ adversely affects its workability due to the high specific surface area [29]. In considering the characteristics of the two constituents (fly ash and nano$\mathrm{SiO}_{2}$ ), the benefit of each material can help counteract the shortcoming of the other: reactive nanoSiO $\mathrm{S}_{2}$ can improve the early-age mechanical properties while fly ash can improve flowability.

When considering the enhancing effect of nanoSiO ${ }_{2}$ on strength gain, most studies thus far have focused on the early-age strength gain $[9,26]$. However, some contradicting results have been reported for the later-age strength development [7]. The lower strength of nanoSiO${ }_{2}$-modified mixes compared to the control at later ages is typically attributed to the dispersion of the nanoparticle and the production technique of the nanoSiO 2 [7,30]. Considering that high amounts of $\mathrm{Ca}(\mathrm{OH})_{2}$ can be consumed by nanoSiO ${ }_{2}$ in the early age, resulting in a lower $\mathrm{Ca}(\mathrm{OH})_{2}$ content for later-age pozzolanic reaction of fly ash, the influence of nanoSiO $\mathrm{S}_{2}$ on the later-age strength of high volume fly ash cementitious materials may be significant. Thus, their effect on the later-age mechanical properties needs further investigation. The results of an in-depth study on the mechanisms underlying the effect of colloidal nanoSiO $\mathrm{S}_{2}$ on the fresh and hardened properties of fly ash-cement system are discussed here.

\subsection{Fresh properties}

The effect of CNS dosage on the slump flow of fly ash-cement mortars is shown in Fig. 8. Mortars were prepared with a sand-

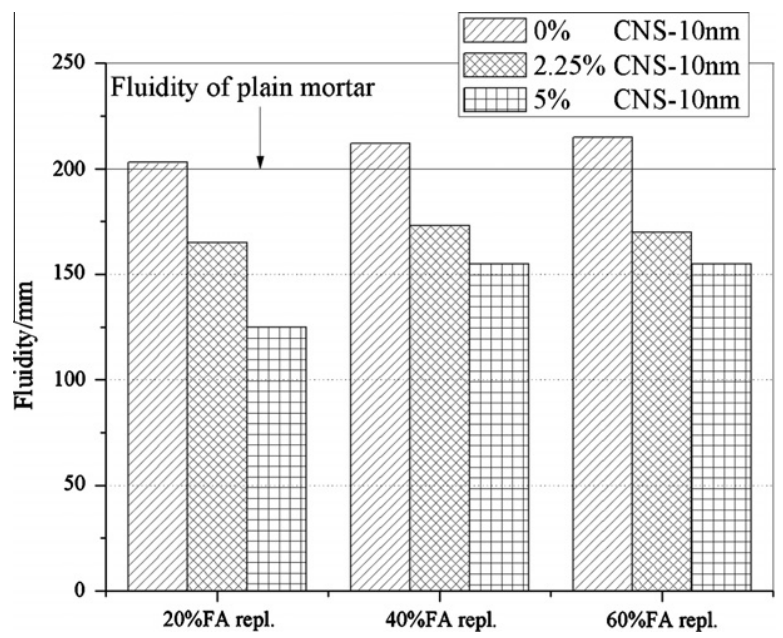

Fig. 8. Influence of CNS on the slump flow of fly ash-cement mortar $(w / b=0.5$, cement to sand ratio $=1: 3$ ). 

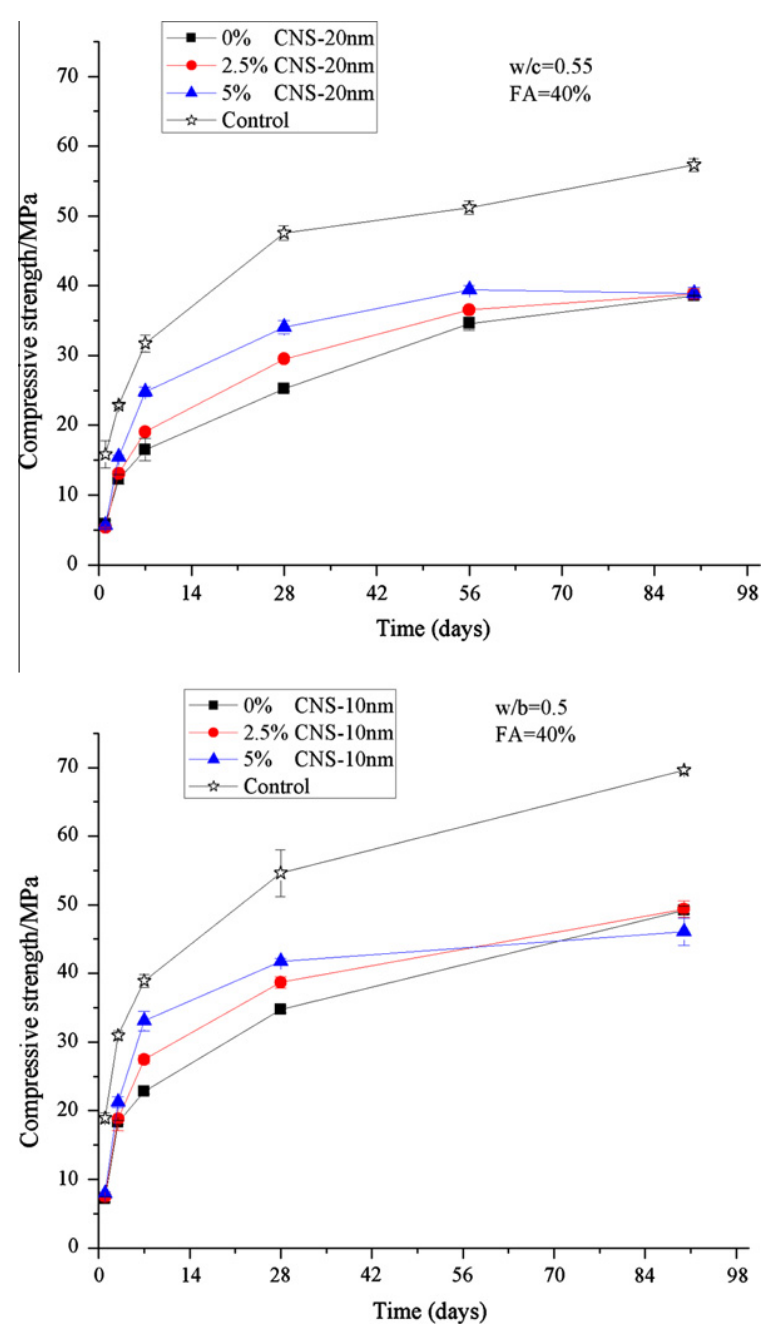

Fig. 9. Effect of CNS on the compressive strength of fly ash mortar.

to-binder ratio of 3 and a $w / b=0.5$. River sand with a modulus of 2.8 was used. As expected, fluidity increased with fly ash replacement and decreased with CNS. The greater the amount of CNS, the greater the reduction in fluidity. It is also shown that the fluidity of CNS-added fly ash mortars with $40 \%$ and $60 \%$ of fly ash replacement are higher than that of $20 \%$ fly ash replaced mortar. This demonstrates that fly ash can help to increase the workability of CNS-added cement-based materials.

\subsection{Compressive strength}

The compressive strength evolution of CNS-added cement-fly ash mortars is shown in Fig. 9. For the $40 \%$ fly ash-cement mortar, the addition of CNS significantly increased the strength gain early on - after 7 days, the compressive strength of 5\% CNSadded fly ash mortar was improved by more than $60 \%$. However, the enhancing effect gradually decreased over time and after 3 months the compressive strength of CNS-added mortar was equal to (CNS-20 nm mortar) or less than (CNS-10 nm mortar) the control fly ash-cement mortar. This implies that nanoSiO has no positive effect on the strength gain of fly ash replaced cement-based material at later ages. To determine why, the hydration and morphology of CNS-modified fly ash-cement systems were closely examined.

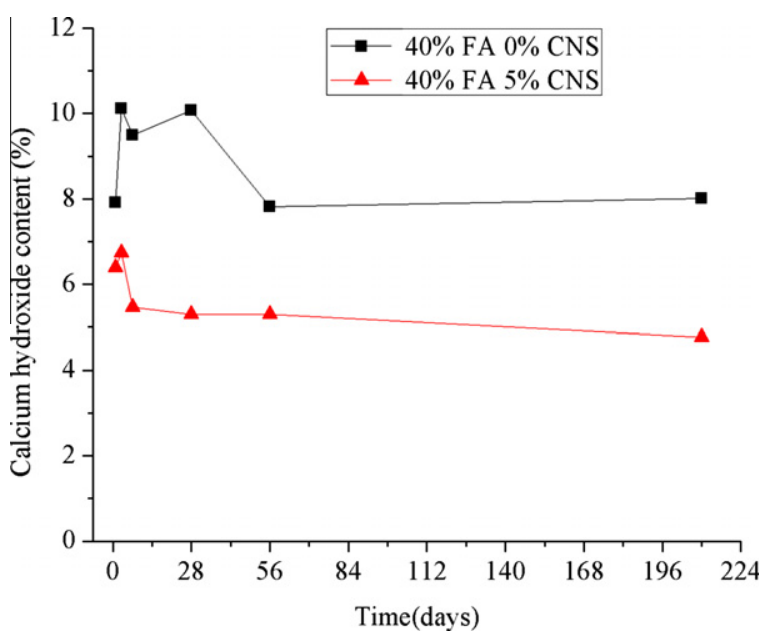

Fig. 10. $\mathrm{Ca}(\mathrm{OH})_{2}$ content vs. time (CNS-10 nm).

\subsection{Hydration mechanism}

\subsection{1. $\mathrm{Ca}(\mathrm{OH})_{2}$ content}

For fly ash replaced cement-based materials, $\mathrm{CH}$ generated by cement hydration is critical for later-age pozzolanic reaction. It can be seen in Fig. 10 that CNS addition has a great influence on the $\mathrm{CH}$ content of fly ash-cement paste. At each age, the $\mathrm{CH}$ content of the $5 \%$ CNS-10 nm paste was lower than that of the $0 \%$ $\mathrm{CNS}$ paste. The greater $\mathrm{CH}$ consumption of $5 \% \mathrm{CNS}$ paste is due to the additional pozzolanic reaction by the CNS. Moreover, it is interesting to note that more $\mathrm{CH}$ was consumed in the $0 \% \mathrm{CNS}$ fly ash paste at later ages (28-56 d), indicating that further pozzolanic reaction of fly ash had occurred. The depletion of $\mathrm{Ca}(\mathrm{OH})_{2}$ could be more severe when the nanoSiO${ }_{2}$ dosage and fly ash replacement ratio are high: a complete $\mathrm{Ca}(\mathrm{OH})_{2}$ depletion can be observed when $7.5 \%$ and $5 \%$ CNS-20 nm are added to $40 \%$ and $60 \%$ fly ash-cement pastes after curing in a $70^{\circ} \mathrm{C}$ water bath for 7 days. Although it has been reported that nanoSiO ${ }_{2}$ is beneficial for the hydration of fly ash in the early age [30], a lack of calcium hydroxide prohibits the hydration of fly ash in the later age and is likely a contributing factor to the reduced rate in long-term compressive strength gain of CNS-modified fly ash-cement mortar.

\subsubsection{Morphology}

The effect of nanoSiO ${ }_{2}$ on the hydration of fly ash particles and its interface with cement paste after 7 months is shown in Fig. 11. It shows that CNS greatly influenced the hydration of fly ash. After 7 months of hydration, it is apparent that the fly ash particles in the control paste are severely eroded and an abundance of hydration products can be found coating the fly ash particle surface. This implies that a high degree of pozzolanic reaction had occurred. For the CNS-added fly ash paste, it shows that the fly ash particles are more smooth and featureless, indicating less pozzolanic activity. A distinct difference in morphology can be seen at the interface of the fly ash particle and cement paste between the two samples. For $0 \%$ CNS paste, the hydrates covering the fly ash surface are well-compacted rods and grains, which is typical for hydration products of mature cement pastes. However, for $5 \%$ CNS-10 nm paste, there is a double-layer shell structure coating the fly ash particle. A close examination of the double-layer shell reveals that it is composed of an outer layer of finely compacted grains and a fibrous inner layer. The EDS results at 15 different areas of the compacted shell structure revealed an average $\mathrm{Ca} / \mathrm{Si}$ ratio of 1.38 , which is smaller than that of the adjacent $\mathrm{C}-\mathrm{S}-\mathrm{H}$ gel of 1.66 ( $\mathrm{Al}$ 


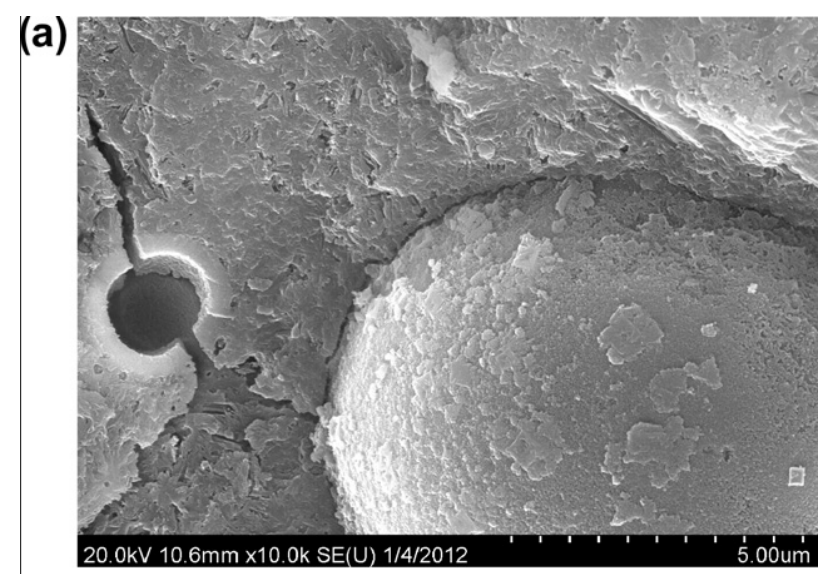

(b)

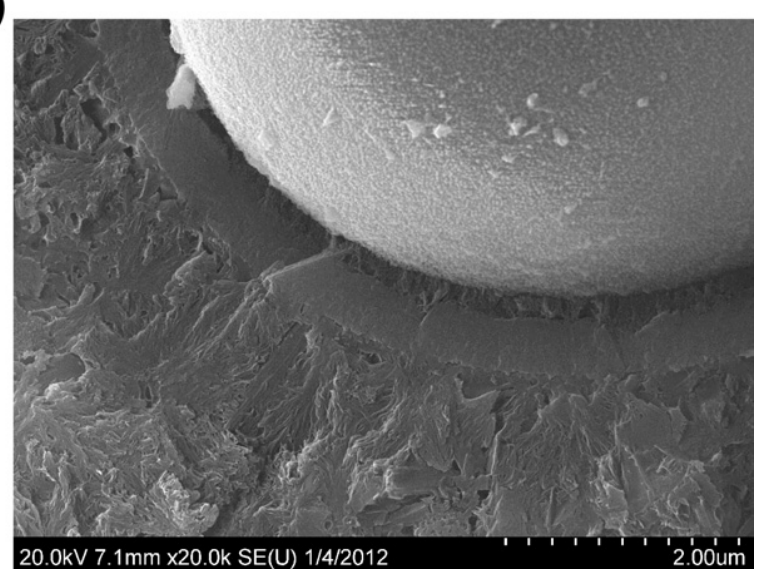

Fig. 11. Interface of cement paste and fly ash particle ( 7 months old) with (a) $0 \%$ CNS and (b) $5 \%$ CNS $-10 \mathrm{~nm}$.

and Fe were assumed to be evenly distributed and were not taken into consideration in the calculation). It has been reported that $\mathrm{C}-\mathrm{S}-\mathrm{H}$ gel with a low $\mathrm{Ca} / \mathrm{Si}$ ratio is less permeable [31]. Thus, it can be deduced that the outer layer of compacted hydrates, which is formed by the pozzolanic reaction of CNS and $\mathrm{CH}$, acts as an ion penetration barrier that hinders the hydration of fly ash particles. The inner fibrous hydrates can be formed by the pozzolanic reaction of fly ash.

From the above investigation, it can be concluded that the reaction of CNS in the early age can result in a low $\mathrm{CH}$ content and a less-permeable gel coating the fly ash particle surface, both of which can limit the hydration of fly ash. This can explain the slowed rate of strength gain exhibited by CNS-added fly ash cement paste at later ages.

\section{Conclusions}

This paper was a summary of the current work being done at ACBM-NU on nanomodification of cement-based materials. Shear rheology results indicated that nanoclays have an immediate stiffening effect, governed by flocculation not water adsorption, but little influence over time. Similarly, clays have a significant effect on the instantaneous formwork response, and thereby maximum pressure, making them effective in reducing SCC formwork pressure. Addition of nanoCaCO 3 was found to accelerate rate of hydration, setting time, and improve compressive strength. Sonication enhanced the effect of the nanoCaCO 3 in all cases. Although early-age strength gain of fly ash-cement systems can be enhanced by nanoSiO${ }_{2}$, rate of later-age strength gain is slowed down. A critical reason may be a lower hydration degree of fly ash in the later age due to a low $\mathrm{Ca}(\mathrm{OH})_{2}$ content and a low $\mathrm{Ca} / \mathrm{Si}$ hydrate barrier coating on fly ash particle, both caused by the hydration of CNS in the early age.

\section{Acknowledgements}

The authors would like to acknowledge the financial support from both the Infrastructure Technology Institute at Northwestern University and Tennessee Valley Authority (TVA) and Oak Ridge Associated Universities (ORAU) (Award 105866). The second author would also like to thank China Scholarship Council for its financial support during his stay at Northwestern University.

\section{References}

[1] Konsta-Gdoutos MS, Metaxa ZS, Shah SP. Highly dispersed carbon nanotube reinforced cement based materials. Cem Concr Res 2010;40(7):1052-9.

[2] Jayapalan AR, Lee BY, Fredrich SM, Kurtis KE. Influence of additions of anatase $\mathrm{TiO}_{2}$ nanoparticles on early-age properties of cement-based materials. J Transportation Res Board 2010;2141:41-6.

[3] Nazari A, Riahi S. The effects of zinc dioxide nanoparticles on flexural strength of self-compacting concrete. Compos Part B: Eng 2011;42(2):167-75.

[4] Sato T, Beaudoin JJ. The effect of nano-sized $\mathrm{CaCO}_{3}$ addition on the hydration of OPC containing high volumes of fly ash. In: Proceedings of the 12th international congress on the chemistry of cement. Montreal, Canada; 2006. p 1-12.

[5] Sato T, Diallo F. Seeding effect of nano- $\mathrm{CaCO}_{3}$ on the hydration of tricalcium silicate. J Transportation Res Board 2010;2141:61-7.

[6] Chang TP, Shih JY, Yang KM, Hsiao T-C. Material properties of portland cement paste with nano-montmorillonite. J Mater Sci 2007;42(17):7478-87.

[7] Gundogdu D, Pekmezci BY, Atahan HN. Influence of nanosilica on the mechanical properties of mortars containing fly ash. Inter RILEM Conf Mater Sci Additions Improving Prop Concr (AdIPoC) 2010;3:345-54.

[8] Shih JY, Chang TP, Hsiao TC. Effect of nanosilica on characterization of Portland cement composite. Mater Sci Eng: A 2006;424(1-2):266-74.

[9] Jo BW, Kim CH, Tae GH, Park JB. Characteristics of cement mortar with nano$\mathrm{SiO}_{2}$ particles. Construction Building Mater 2007;21(6):1351-5.

[10] Nazari A, Riahi S. The effects of $\mathrm{SiO}_{2}$ nanoparticles on physical and mechanical properties of high strength compacting concrete. Compos Part B: Eng 2011;42(3):570-8.

[11] Qing Y, Zenan Z, Deyu K, Rongshen C. Influence of nano-SiO2 addition on properties of hardened cement paste as compared with silica fume. Construction Building Mater 2007;21(3):539-45.

[12] Sobolev K, Flores I, Torres-Martinez LM, Valdez PL, Zarazua E, Cuellar EL. Engineering of SiO2 nanoparticles for optimal performance in nano cementbased materials. In: Bittnar Z, Bartos PJM, Němeček J, Šmilauer V, Zeman J, editors. Nanotechnology in construction 3. Berlin Heidelberg: Springer; 2009. p. $139-48$.

[13] ASTM C 191 - 08, Standard test method for time of setting of hydraulic cement by Vicat needle. West Conshohocken, PA: ASTM International; 2008.

[14] ASTM C 230 - 08. Standard specification for flow table for use in tests of hydraulic cement. West Conshohocken, PA: ASTM International; 2008.

[15] ASTM C 109/C 109M-08. Standard test method for compressive strength of hydraulic cement mortars (using 2-in. or [50 mm] cube specimens). West Conshohocken, PA: ASTM International; 2008.

[16] Pekmezci BY, Voigt T, Kejin W, Shah SP. Low compaction energy concrete for improved slipform casting of concrete pavements. ACI Mater J 2007;104 (Compendex):251-8.

[17] Tregger N, Voigt T, Shah S. Improving the slipform process via material manipulation. In: Grosse CU, editor. Advances in construction materials 2007. Berlin Heidelberg: Springer; 2007. p. 539-46.

[18] Tregger N. Tailoring the fresh state of concrete. PhD Thesis, Evanston, IL: Northwestern University; 2010.

[19] Voigt T, Mbele JJ, Wang K, Shah SP. Using fly ash, clay, and fibers for simultaneous improvement of concrete green strength and consolidatability for slip-form pavement. J Mater Civil Eng 2010;22(2):196-206.

[20] Kim JH, Beacraft M, Shah SP. Effect of mineral admixtures on formwork pressure of self-consolidating concrete. Cem Concr Compos 2010;32(9): 665-71.

[21] Tregger NA, Pakula ME, Shah SP. Influence of clays on the rheology of cement pastes. Cem Concr Res 2010;40(Compendex):384-91.

[22] Ferron R. Formwork pressure of self-consolidating concrete: influence of flocculation mechanisms, structural rebuilding, thixotropy and rheology. PhD Thesis, Evanston, IL: Northwestern University; 2008.

[23] Kawashima S, Kim JH, Corr D, Shah SP. Study of the mechanisms underlying the fresh-state response of cementitious materials modified with nanoclays. Constr Build Mater, in press.

[24] Kim JH, Beacraft M, Kwon SH, Shah SP. Simple analytical model for formwork design of self-consolidating concrete. ACI Mater J 2011;108(1):38-45.

[25] Kwon SH, Shah SP, Phung QT, Kim JH, Lee Y. Intrinsic model to predict formwork pressure. ACI Mater J 2010;107(1):20-6.

[26] Li H, Xiao HG, Yuan J, Ou J. Microstructure of cement mortar with nanoparticles. Compos Part B: Eng 2004;35(2):185-9. 
[27] Thomas JJ, Jennings HM, Chen JJ. Influence of nucleation seeding on the hydration mechanisms of tricalcium silicate and cement. J Phys Chem C 2009;113(11):4327-34.

[28] Ji T. Preliminary study on the water permeability and microstructure of concrete incorporating nano-SiO 2 . Cem Concr Compos 2005:35(10):1943-7.

[29] Sobolev K, Flores I, Hermosillo R, Torres-Martinez LM. Nanomaterials and nanotechnology for high-performance cement composites. In: Nanotechnology of concrete: recent developments and future perspectives - ACI Fall 2006 convention, November 8, 2006, American Concrete Institute. p. 93-120.

[30] Li G. Properties of high-volume fly ash concrete incorporating nano-SiO ${ }_{2}$. Cem Concr Compos 2004;34(6):1043-9.

[31] Garrault S, Nonat A. Hydrated layer formation on tricalcium and dicalcium silicate surfaces: experimental study and numerical simulations. Langmuir 2001;17(26):8131-8. 